\title{
The Factors Affecting the Decision to Participate in Voluntary Social Insurance of Vietnamese Employees: The Case of Tra Vinh Province
}

\author{
Ha Hong Nguyen ${ }^{1}$, Trung Thanh Nguyen ${ }^{2} \&$ Phong Thanh Nguyen ${ }^{3}$ \\ ${ }^{1}$ Department of Finance and Banking, Tra Vinh University, Viet Nam \\ ${ }^{2}$ Tra Vinh University, Viet Nam \\ ${ }^{3}$ Lien Viet Post Joint Stock Commercial Bank Tra Vinh Branch, Viet Nam \\ Correspondence: Ha Hong Nguyen, Ph.D. Lecturer; Head of Department of Finance and Banking, Tra Vinh \\ University, Viet Nam. Tel: 84-2943-855-246.
}

Received: November 14, 2019

Accepted: December 10, 2019

Online Published: December 17, 2019

doi:10.5430/rwe.v10n3p431

URL: https://doi.org/10.5430/rwe.v10n3p431

\begin{abstract}
The purpose of this study is to find out the factors affecting the decision on participation in voluntary social insurance of non-state sector employees. To propose such recommendations to the Vietnam Government and Social Insurance of Vietnam, to develop a voluntary insurance policy, improve social security for non-state workers in Vietnam. The analysis of factors affecting the decision to participate in voluntary social insurance of Vietnamese employees in the case of Tra Vinh province by using the method of primary data collection of 300 employees in Tra Vinh province; using multivariate regression methods. The study has found 9 factors such as: social security awareness, the attitude of the employees, knowledge of voluntary social insurance of the employees, the social influence of voluntary social insurance, income of employees, social media, voluntary social insurance policy, Adult's health awareness in old age and moral responsibility affecting the decision to participate in voluntary social insurance of the employees in Tra Vinh province. Then, the authors have proposed implicational policies such as enhancing communication work for employees, building flexible social insurance policies, diversifying types of payments, Focusing on awareness education about Vietnam social security,...contributing to ensuring social security for Vietnamese employees when they reach the retirement age.
\end{abstract}

Keywords: decision, voluntary social insurance, employees, Tra Vinh City, social security

JEL Classification code: G22 I31, I38, J26, J30

\section{Introduction}

Social insurance in our country is one of the major policies in the Social Security system of the Party and the State. Besides compulsory social insurance, voluntary social insurance takes effect from January 1, 2008, open opportunities for freelance employees to contribute to social insurance. Participating in voluntary social insurance, freelance employees with low and unstable incomes will enjoy pensions, contributing to ensuring the life of old age. (Vietnam Social Insurance 2019). Plan No. 93-KH / TU dated August 17, 2018, of the Standing Committee of Tra Vinh Provincial Party Committee on the implementation of Directive No. 28-NQ / TW of the Party Central Committee (XII) "on reform social insurance policy" requires the participation rate of voluntary social insurance must reach from $1 \% ; 2.5 \% ; 5 \%$ corresponding to the year $2021 ; 2025 ; 2030$. However, according to the data reported by Tra Vinh Social Insurance, by the end of 2018, the percentage of voluntary social insurance participation in the whole province was only $0.32 \%$ of the total working-age population. (Ministry of Labor - Invalids and Social Affairs, 2010)

Since the implementation of the voluntary Social Insurance in 2008, by the end of 2018, Tra Vinh province had 203 participants, accounting for $0.34 \%$ of the total working-age population, which included those who have had time to work to participate in compulsory social insurance want to pay more to qualify to enjoy the retirement regime. This number can be too small compared to the potential and expectations of the functional industry. The causes are related to many issues such as education level, social awareness, precarious jobs, low income ... Since then, workers have not considered social insurance as an urgent need. (Social Insurance of Tra Vinh Province, 2019). 


\section{Literature Review}

Nguyen Ngoc Thu Thao (2017), through collecting 360 primary data samples, with quantitative research methods, after testing the model by correlation analysis, regression analysis, the authors have pointed out that there are seven factors such as attitudes, knowledge, expectations of family, moral responsibilities, perceived risks, income, and age affecting the decision on participation in the voluntary social insurance of small traders and retailers in Ben Tre province.

Huynh Minh Dat (2016) surveyed 139 employees with questionnaires and after processing the data, formulating a formal regression model that concluded that factors: social security awareness, attitude, and knowledge about voluntary social insurance, social impacts, income, and media effect local employees' decision to participate in voluntary social insurance. Le Canh Bich Tho, Truong Thi Thanh Tam and Vo Van Tuan (2017) collected data by interviewing in a structured questionnaire with 207 respondents living in 3 districts of Can Tho city: Ninh Kieu, Binh Thuy, and Cai Rang. The research results show that health status, gender, education level, propaganda, and the number of medical examinations and treatment affect people's decision to buy voluntary health insurance.

Hoang Bich Hong, Mai Thi Huong and To Thi Hong (2017) conducted a study on "Factors affecting voluntary social insurance participation of informal sector employees. The results of the survey and data processing show that the factors of ethical responsibility and media are the two factors that have the strongest impact on the workers' intention to participate in social insurance in the informal sector, not income. Besides, low educational attainment also hinders the understanding of the social insurance policy, as well as the awareness of the ethical responsibilities of the employees.

Truong Thi Phuong and Nguyen Thi Hien (2013) shows that all 6 factors affecting the intention to participate in voluntary social insurance are the perception of social security of voluntary social insurance, attitude, social influence, knowledge of voluntary social insurance, income, and media. Research results of Nguyen Xuan Cuong, Nguyen Xuan Tho and Ho Huy Tua (2014) show that seven factors are affecting the decision to participate in voluntary social insurance: attitudes, family expectations, attention to health when old age, moral responsibility, behavior control, knowledge of voluntary social insurance and propaganda. While in the research of Pham Thi Lan Phuong and Nguyen Van Song (2014), the author pointed out seven reasons why people do not participate in voluntary social insurance. That is, unstable jobs and low incomes (82\%), high insurance premiums (67\%), the time to enjoy the regime is quite long (58\%), the procedures for participation are cumbersome, complicated and not flexible (65\%), lack of information (56\%), lack of trust (27\%), no insurance required (11\%). Research by Pham Thanh Tung (2017) suggests that the voluntary social insurance policy has not attracted workers due to propaganda.

Lin Liyue; Zhu Yu (2006) conducted a survey of 600 workers in six provinces in Fujian Province, showed that the decision to participate in voluntary social insurance depends on the awareness of social security, ethical responsibilities, and an understanding of voluntary social insurance. Meanwhile, Shurong Han (2014) argues that immigrants are willing to take out insurance, if they see their benefits and for the insurance policy of immigrants to be effective, there must be increased oversight in the implementation of policies and propaganda so that the immigrants know and understand the policies and the government must understand the wishes of the workers, and meet the needs of the workers through the policies. Min Qin; Yaer Zhuang; Hongyan Liu (2015) suggested that stable jobs, income and insurance policies of each locality are factors that influence the decision of workers' participation.

The above studies largely refer to the factors affecting the decision to participate in voluntary social insurance in many different localities in Vietnam and abroad of workers in the private and informal sectors. However, the studies rarely use quantitative models to analyze and do not really analyze in depth the existing problems of private sector workers as employees in the free areas and workers in individual business households at a specific province like Tra Vinh. Therefore, the author's research focuses on analyzing these differences specifically.

\section{Research Methodology}

The data of 300 employees were collected in Tra Vinh province, which based on the common theoretical basis and previous studies related to social insurance, the authors also based on the theory of rational action (TRA) of Ajzen, I., Fishbein, M., (1975), and Theory of planned behavior (TPB) of Ajzen, I., (1991) with the profile which explains the decision of voluntary social insurance participation of employees in Tra Vinh province as follows:

In which

$$
Y=\beta_{0}+\beta_{1} X_{1}+\beta_{1} X_{2}+\beta_{3} X_{3}+\beta_{4} X_{4}+\beta_{5} X_{5}+\beta_{6} X_{6}+\beta_{7} X_{7}+\beta_{8} X_{8}+\beta_{9} X_{9}+\varepsilon
$$

- Y: Decision of participating in voluntary social insurance. 
- $\mathrm{X}_{1}, \mathrm{X}_{2}, \mathrm{X}_{3}, \mathrm{X}_{4}, \mathrm{X}_{5}, \mathrm{X}_{6}, \mathrm{X}_{7}, \mathrm{X}_{8}, \mathrm{X}_{9}$ : Factors of participating in voluntary social insurance of employees: The awareness of social security in voluntary social insurance, employees' behaviors, knowledge on voluntary social insurance, social impacts, incomes, communication, families' expectations, health awareness in old ages and moral responsibility.

Table 1. A summary of variable models

\begin{tabular}{|c|c|c|c|c|}
\hline No. & Names of Variables & $\begin{array}{c}\text { Variable } \\
\text { Codes }\end{array}$ & Basics of Variable selection & $\begin{array}{l}\text { Expectations } \\
\text { of Variables }\end{array}$ \\
\hline 1 & $\begin{array}{l}\text { Social security } \\
\text { awareness }\end{array}$ & $\mathrm{X} 1$ & $\begin{array}{l}\text { Truong Thi Phuong \& Nguyen Thi Hien (2013); } \\
\text { Liyue; Zhu Yu (2006); Huynh Minh Dat (2016) }\end{array}$ & + \\
\hline 2 & Employees' behaviors & $\mathrm{X} 2$ & $\begin{array}{l}\text { Ajzen (1991); Nguyen Xuan Cuong, Nguyen } \\
\text { Xuan Tho, Ho Huy Tuu (2014); Nguyen Ngoc } \\
\text { Thu Thao (2017); Huynh Minh Dat (2016); } \\
\text { Truong Thi Phuong, Nguyen Thi Hien (2013). }\end{array}$ & + \\
\hline 3 & $\begin{array}{l}\text { Employees' knowledge } \\
\text { on voluntary social } \\
\text { insurance }\end{array}$ & $\mathrm{X} 3$ & $\begin{array}{l}\text { Pham Thi Lan Phuong, Nguyen Van Song } \\
\text { (2014); Nguyen Ngoc Thu Thao (2017); Huynh } \\
\text { Minh Dat (2016); Truong Thi Phuong, Nguyen } \\
\text { Thi Hien (2013); Nguyen Xuan Cuong, } \\
\text { Nguyen Xuan Tho, Ho Huy Tuu (2014) }\end{array}$ & + \\
\hline 4 & $\begin{array}{l}\text { Social impacts on } \\
\text { voluntary social } \\
\text { insurance }\end{array}$ & $\mathrm{X} 4$ & $\begin{array}{l}\text { Fishbein và Ajzen (1975) ; Đong Quoc Dat } \\
\text { (2008); Huynh Minh Dat (2016); Truong Thi } \\
\text { Phuong, Nguyen Thi Hien (2013) }\end{array}$ & + \\
\hline 5 & Income of Employees & $\mathrm{X} 5$ & $\begin{array}{l}\text { Dong Quoc Dat (2008), Lin Liyue; Zhu Yu } \\
\text { (2006), Min Qin; Yaer Zhuang; Hongyan Liu } \\
\text { (2015); Pham Thi Lan Phuong, Nguyen Van } \\
\text { Song (2014); Nguyen Ngoc Thu Thao (2017); } \\
\text { Huynh Minh Dat (2016); Truong Thi Phuong, } \\
\text { Nguyen Thi Hien (2013) }\end{array}$ & + \\
\hline 6 & Social Media & X6 & $\begin{array}{c}\text { Hoang Bich Hong, Mai Thi Huong, To Thi } \\
\text { Hong (2017); Pham Thi Lan Phuong, Nguyen } \\
\text { Van Song (2014); Le Canh Bich Tho, Truong } \\
\text { Thi Thanh Tam, Vo Van Tuan (2017); Shurong } \\
\text { HAN (2014); Huynh Minh Dat (2016); Pham } \\
\text { Thanh Tung (2017); Truong Thi Phuong, } \\
\text { Nguyen Thi Hien (2013) }\end{array}$ & + \\
\hline 7 & $\begin{array}{l}\text { The policies of } \\
\text { voluntary social } \\
\text { insurance }\end{array}$ & $\mathrm{X} 7$ & $\begin{array}{c}\text { Min Qin, Yaer Zhuang, Hongyan Liu (2015); } \\
\text { Shurong HAN (2014); Pham Thanh Tung } \\
\text { (2017); Pham Thi Lan Phuong, Nguyen Van } \\
\text { Song (2014) }\end{array}$ & + \\
\hline 8 & $\begin{array}{l}\text { Adults' health } \\
\text { awareness }\end{array}$ & $\mathrm{X} 8$ & $\begin{array}{l}\text { Le Canh Bich Tho, Truong Thi Thanh Tam, Vo } \\
\text { Van Tuan (2017); Olsen (2003); Nguyen Xuan } \\
\text { Cuong, Nguyen Xuan Tho, Ho Huy Tuu (2014) }\end{array}$ & + \\
\hline 9 & Moral responsibilities & $\mathrm{X} 9$ & $\begin{array}{c}\text { Nguyen Xuan Cuong, Nguyen Xuan Tho, Ho } \\
\text { Huy Tuu (2014); Nguyen Ngoc Thu Thao } \\
\text { (2017); Hoang Bich Hong, Mai Thi Huong, To } \\
\text { Thi Hong (2017) }\end{array}$ & + \\
\hline 10 & $\begin{array}{l}\text { Decision of } \\
\text { participating in } \\
\text { voluntary social } \\
\text { insurance }\end{array}$ & $\mathrm{Y}$ & From the above studies, and expert surveys & $+/-$ \\
\hline
\end{tabular}

Source: Authors' collection 


\section{Research Results}

Table 2. The results of multiple regression

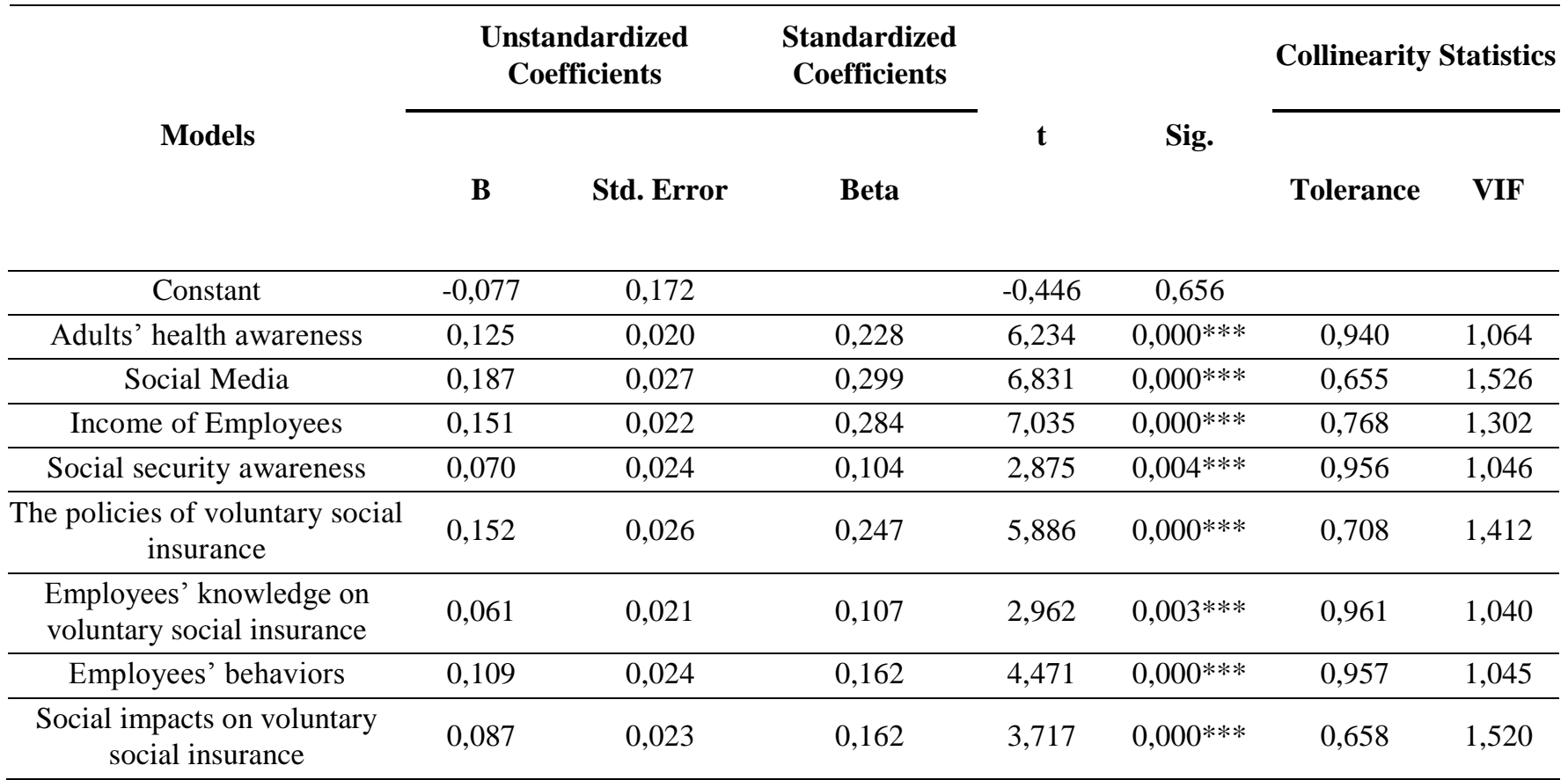

Dependent variables: Decision of participating in voluntary social insurance (***: means level of significance at 99\%)

Source: Survey results and data processing

Decision of participating in voluntary social insurance $=-0.077+0,070 *$ Social security awareness + $0,109 *$ employees' behaviors $+0,061 *$ Employees' knowledge on voluntary social insurance $+0,087 *$ Social impacts on voluntary social insurance $+0,151 *$ Income of Employees $+0,187 *$ Social Media $+0,152 *$ The policies of voluntary social insurance $+0,125^{*}$ Adults' health awareness.

Based on the equation of the multivariate regression model (Hair JF, Tatham RL, Anderson RE and Black W), it can be easily seen that the regression coefficients are all positive signs showing that the factors in the regression model are positively related with the employees' decision to participate in voluntary social insurance, when the awareness of social security increases by 1 and other factors that do not change, the employes' decision to participate in voluntary social insurance increased by 0.070 points. The Employees' Attitude factor increased by 1 and the other factors did not change, the employees' decision to participate in voluntary Social Insurance increased by 0.1109 points. The Union of Workers increases by 1 and the other factors remain unchanged, the decision to join Social Insurance Voluntary Workers increased 0.061 points.

The Income factor increased by 1 and the other factors remain stable, the employees' decision to participate in voluntary Social Insurance increased to 0,151 points. The Communication factor increased by 1 and the other factors stayed the same, the employees' decision to participate in voluntary Social Insurance increased to 0.187 points. The factor of voluntary social insurance policy increased by 1 and other factors did not change, the employees' decision to participate in voluntary social insurance increased to 0.152 points. The Social Security Awareness factor increased by 1 and the other factors did not change, the employees' decision to participate in voluntary Social Insurance increased by 0.070 points. Employees' responsibility factor increased by 1 and other factors did not change, the employees' decision to participate in Voluntary Social Insurance increased by 0.125 points. 


\section{Suggestions of Policies to Improve the Voluntary Social Insurance Participation of Employees}

\subsection{Enhancing Communication Collaboration}

It cannot be denied that social insurance at all levels should be coordinated with functional agencies, press agencies, television and radio stations to broadcast the information and communication work so well that people can understand and participate in voluntary social insurance, because the subject of voluntary social insurance is very diverse, most of them have never participated in social insurance. Generally speaking, it is necessary to mobilize many people to change their mindset to take care of their present work without worrying much of the future ones, overlooking the participation in voluntary social insurance so that they can enjoy pensions and benefits when they can enjoy from Health Insurance when they are old.

It can be vital that the provincial Social Insurance Agency should build an agent specializing in the development of voluntary social insurance objects, and the Post Office can be the unit which is capable of meeting that condition, at present, in addition to the advantage of having a post office system at the commune level, the Post Office is cooperating with social insurance in the payment of pensions, social insurance benefits and is a collection agent of voluntary health insurance and social insurance.

\subsection{Building Flexible and Attractive Voluntary Social Insurance Policies}

This is a form of non-commercial Social Insurance to support the community, especially to those who have low incomes when they get old, receive a corresponding amount of money and enjoy medical care from the State. Although it has created favorable conditions for people to participate in voluntary social insurance by offering a diverse and abundant method of voluntary social insurance (monthly, quarterly, yearly, one-time payment), the benefits of voluntary social insurance participants currently only have two retirement and survivorship regimes which are not satisfactory, employees need to have more suitable choices of benefits such as women who want to receive maternity benefits; domestic workers who want a sickness regime; blue collars need the labor accident regime and so on for themselves.

\subsection{Depending on the Incomes of Each Local Employee to Build an Appropriate Fee}

From 2018, although the State supports the voluntary social insurance premium by $30 \%$ for poor households, $25 \%$ for linear-poor households and $10 \%$ for those who are still poor above the monthly social insurance premium based on the poverty line of rural areas, but that support is still very low; Those who are poor and linear-poor households, even though they receive higher support, are also unable to participate. Therefore, the Social Insurance Agency should propose and propose to the National Assembly, the Government and the Ministry of Labor, War Invalids and Social Affairs to study the reduction of fees and at the same time increase the supportive level for the participants of Voluntary Social Insurance associations, especially other subjects not from poor and near-poor households. This is a large labor force in Tra Vinh province in particular and Tra Vinh province in general, with incomes from 4 million to less than 8 million (192/279 people, accounting for $68.8 \%$ of the total number of observed samples), they do not belong to the poor and linear-poor level but have decided to participate in voluntary social insurance as analyzed in the above income differences.

\subsection{Educating Employees' Sense of Responsibility When They Retire}

There should be more attentions to those who are aged 36-45. They should be encouraged to have a sense of responsibility to their families and are able to decide to participate in voluntary social insurance with a stable income. If a part-time group of activities is not eligible for compulsory social insurance, participating in voluntary social insurance is considered as a meaningful decision for itself and shows responsibility to the family, community, society and the States.

\subsection{Training the Attitudes of People Participating in Voluntary Social Insurance}

At present, it can be stated that employees have a clear sense of responsibility to take care of themselves when they get older, less dependent on their descendants as traditionally held in the past, to match that trend, choosing to join Insurance Voluntary society can derivavte a stable financial source and enjoy the health insurance policy when they get old. Participating in voluntary social insurance can be strongly considered as an expression of responsibility for oneself, family and community. Supportive services and reasonable policies must be improved so that they recognize that the costs of voluntary Social Insurance is appropriate to their conditions and incomes and the benefits that are more than the value that they have missed out.

\subsection{Social Impacts of Voluntary Social Insurance}

In modern society with the strong supports of information technology, the more people are aware of the problems and the necessity of voluntary social insurance policies, the speed of their rapid impact on others are a great advantage, because family members or those who have been satisfied with voluntary social insurance. They will 
become an effective communication channel to their relatives and local people because it can be obvious that they know how to communicate and interpret the problems in the most effective and efficient ways.

The key figures influencing the employee's intentions to participate in voluntary social insurance may be family members, friends, colleagues, media, and so on. Their contributions to voluntary social insurance also contribute to the employees' decision to participate with different strengths depending on the employees' relationship and respect the influential groups.

\subsection{Focusing on Awareness Education About Vietnam Social Security}

Strengthening the advocacy campaign so that employees can easily learn about the increasing social risks along with the development of modern life and participating in voluntary social insurance to accumulate and take care of their future. Voluntary Social Insurance is the State's social security policy which is suitable for employees at the end of their working age. It can be attended more on strengthening awareness of Social Security for farmers, peasants and mannual workers because these groups can have little access to government's policies, especially the concept of Social Security. It can be very necessary for them to understand that participating in Social Insurance is essential for themselves, for their family members, and this is not for business purposes.

\subsection{Disseminating Strong Voluntary Social Insurance to Employees in Private Area}

It can be necessary for Social Insurance of Tra Vinh province to enhance education and propaganda to employees about the voluntary social insurance policies and guide them on the procedures and benefits of participating in Social Insurance. It is very important to increase the number of people enrolled in voluntary social insurance. Therefore, the Social Insurance Agency needs to train the propaganda team with skills, knowledge and good care for "customers" to advise them about the policies, help them understand the benefits of joining voluntary Social Insurance which will ensure their lives in the future. The difference in educational attainment indicates that the high school group has a strong decision to participate, it can be very vital to focus on increasing the understanding of the groups at the primary and lower secondary levels by approaching communication. They can have a nice belief of giving them a better insight and sympathy about the voluntary social insurance policy in private area.

\section{Acknowledgements}

The authors sincerely thank the support and assistance of the survey team of Faculty of Economics, Tra Vinh University; Social Insurance of Tra Vinh Province, Viet Nam, and 300 employees working outside outside Enterprises in Tra Vinh Province. The authors sincerely thank the enthusiastic support of these research groups.

\section{References}

Ajzen, I. (1991). The theory of planned behavior. Organizational Behavior and Human Decision Process, 50, 179-211.

Ajzen, I., \& Fishbein, M. (1975). Belief, Attitude, Intention, and Behavior. Addison-Wesley Publishing Company, Inc., pp. 121-156.

Dong, Q.D. (2008). Unofficial regional social insurance in Vietnam, situation and recommendations. Journal of Economics and Forecasting, (15), 23-29.

Hair, J.F., Tatham, R.L., Anderson, R.E., \& Black, W. (1998). Multivariate Data Analysis (5th ed.). New Jersey: Prentice-Hall, Inc., pp. 24-29.

Han, S. (2014). Migrant Workers' Old-age Insurance Policy in China: Beyond an Economic Development Perspective. The University of Adelaide, 21-28.

Hoang, B.H., Mai, T.H., \& To, T.H. (2017). Factors affecting social insurance participation of informal sector workers. Social Insurance Magazine, (3B), 12-19.

Huynh, M.D. (2016). Determining factors affecting the voluntary social insurance participation of employees in Cang Long district. Master of thesis, Tra Vinh University, pp. 34-39.

Le, C.B.T., Vo, V.T., \& Truong, T.T.T. (2017). Factors affecting the decision to buy voluntary health insurance from Can Tho people. Journal of Science Can Tho University, (48), 20-25.

Lin, L., \& Zhu, Y. (2006). Housing conditions of the floating population under the double residential status and the factors affecting them a case study in Fujian Province. Population Research, (3), 48-57.

Min, Q., Yaer, Z., \& Hongyan, L. (2015). Old age insurance participation among rural-urban migrants in China. Demographic research, 33(37), 1047-1066. 
Ministry of Labor - Invalids and Social Affairs. (2010). Social Security Strategy 2011-2020, pp. 10-12.

Nguyen, N.T.T. (2017). Factors affecting the decision on participation in voluntary social insurance of small and retail traders in Ben Tre province. Master of thesis, Nha Trang University, pp. 28-32.

Nguyen, X.C., Nguyen, X.T., \& Ho, H.T. (2014). Some factors affecting the voluntary social insurance participation of small traders in Nghe An province. Journal of Viet Nam National Economics University Science, Economics and Business, 30(1), 36-45.

Olsen, S.O. (2003). Understanding the relationship between age and seafood consumption: The mediating of attitude, health involment and convenience. Food Quality and Preference, 14, 199-209.

Pham, T.L.P., \& Nguyen, V.S. (2014). The situation of voluntary social insurance participation of people in Vinh Phuc province. Journal of Science and Development, 12(5), 787-795.

Pham, T.T. (2017). Solutions for developing voluntary social insurance participants in Quang Binh province. Quang Binh Journal of Science and Technology Information, (5), 31-37.

Social Insurance of Tra Vinh Province. (2019). Summary report of 05-year work for the period of 2014-2018, 02-04.

Truong, T.P., \& Nguyen, T.H. (2013). Factors affecting voluntary social insurance participation of informal sector workers in Phu Yen province. Journal of Fisheries Science and Technology, (2), 181-186.

Viet Nam Social Insurance. (2019). Summary of 2018 and implementation of 2019 tasks of the social insurance agency of Tra Vinh province, pp. 03-08. 